\title{
EDITORIAL
}

\section{CPD and the portfolio psychiatrist}

\author{
John Gunn
}

\begin{abstract}
As the age at which psychiatrists leave the National Health Service falls, and as the importance of CPD grows, there is an increasing urgency to assist the professional development and the licensing of portfolio practitioners. A survey undertaken to gain an impression of the experiences of this group of members of the Royal College of Psychiatrists highlighted considerable difficulties for some. Recommendations are made here both for individual members and for the CPD structures within the College. In particular, it is suggested that the College help with the appraisal of members who are outside managed organisations and that enhanced responsibilities be given to regional CPD coordinators. Individual members should see the peer group as the centre of their CPD activities, take a flexible approach to their own CPD, and advise other members of their peer group accordingly.
\end{abstract}

In recent years, the Royal College of Psychiatrists' Director of Continuing Professional Development (CPD) and his committee have become concerned that some groups of psychiatrists, particularly 'portfolio psychiatrists' (Box 1), are failing to register for CPD and failing to send in forms saying that they are in good standing with their colleagues as far as professional development is concerned. This is a matter of increasing importance as the profession comes under ever greater criticism and governments try to impose their own standards of professional practice for UK doctors.

To investigate this I carried out a survey in 2004 of members of the Royal College of Psychiatrists who were known to be over 60 years of age and retired from practice or not working for the NHS (Gunn, 2005). This is not a complete sample as I used the College database, which is dependent on the information supplied by individual members, who do not always inform the College of changes.

\section{Box 1 Portfolio members}

Portfolio members of the College are those who those who have retired from the National Health Service (NHS), but continue to work part-time, often in several capacities. In the survey described here this group was captured by contacting all members who said they were not in full-time NHS practice.
Of the 1369 questionnaires sent out by mail, 735 (54\%) were returned. Of the respondents, 359 said that they were retired, 73 said they were employed in the independent sector, 173 said they were self-employed or in private practice, and 44 that they were working mainly in the NHS (either choosing to retire beyond 60 , or doing locum work); 78 members formed a heterogeneous group engaged in 'other activities' such as mental health tribunal work (probably the largest subgroup), work for the Parole Board, work as Mental Health Act commissioners, second opinion doctors for the Mental Health Act, voluntary unpaid work, supervision of other psychiatrists, particularly psychotherapists, examination work for the College, work for the civil service and for the Ministry of Defence, work in the Channel Islands, work for the Midwifery and Nursing Council, teaching and research.

\section{Summary of findings}

The survey has been reported at one or two College meetings and its results have been published on the College website (http: / / www.rcpsych.ac.uk/docs / RetiredMembersurveyreportOct05.doc). Just to give a rough impression of the findings, I discuss here the overall, amalgamated, result (Table 1).

Only 393 of the surveyed members (just over half) wanted to keep their licence; these are the ones whose answers were analysed. As Table 1 shows, $17 \%$ of them were not doing CPD and $55 \%$ said they

John Gunn is Emeritus Professor of Forensic Psychiatry at the Institute of Psychiatry and currently a member of the Parole Board of England and Wales. Correspondence: c/o Advances in Psychiatric Treatment, Royal College of Psychiatrists, 17 Belgrave Square, London SW1X 8PG, UK. 
Table 1 Amalgamated results of a survey of 393 portfolio psychiatrists

\begin{tabular}{lccccccc} 
& \multicolumn{2}{c}{ Yes } & \multicolumn{3}{c}{ No } & \multicolumn{3}{c}{ Not known } \\
Question & $n$ & $\%$ & $n$ & $\%$ & $n$ & Total \\
Licence wanted? & 393 & 53 & 328 & 47 & 14 & 735 \\
Doing CPD? & 300 & 83 & 93 & 17 & 0 & 393 \\
Familiar with CPD rules? & 321 & 82 & 69 & 18 & 3 & 393 \\
Difficulties with CPD? & 136 & 45 & 156 & 55 & 8 & 300 \\
In a peer group? & 249 & 83 & 49 & 17 & 2 & 300 \\
Group includes NHS doctors? & 149 & 60 & 100 & 40 & 0 & 249 \\
Group is all same specialty? & 148 & 60 & 99 & 40 & 2 & 249 \\
Knows name of regional coordinator? & 107 & 27 & 272 & 73 & 14 & 393 \\
Sought advice from regional coordinator? & 30 & 28 & 77 & 72 & 0 & 107 \\
Would like College appraisal? & 240 & 61 & 70 & 39 & 83 & 393 \\
Willing to pay for College appraisal? & 203 & 86 & 21 & 14 & 16 & 240
\end{tabular}

had difficulties with doing CPD. Of the ones who said they were doing CPD, $17 \%$ did not belong to a CPD peer group, despite the fact that the College $\mathrm{CPD}$ system requires this. Almost three-quarters of the 393 did not know the name of the regional coordinator for CPD and consequently only 30 people had ever sought advice from the regional coordinator. Of the members hoping to keep their licence, $86 \%$ said they would be willing to pay for a College appraisal.

There were marked differences between the subgroups: members working for the independent sector reported having much less difficulty in carrying out CPD than those who were retired from the NHS or still working for it. This last comment seems very odd until it is realised that most of the members in this group were doing locum work for the NHS and not getting the same opportunities as fully contracted practitioners get, i.e. paid leave to undertake educational activities and travel expenses. A lack of these opportunities was also cited as a serious obstacle by some members who had retired from the NHS or were in private practice. Private practitioners sometimes pointed out in their comments that not only did they have to pay for all educational activities themselves but they lost income while engaged in them.

Perhaps the most surprising adverse comment that emerged quite prominently among both members who had retired from the NHS and other private practitioners was the difficulty in finding a CPD peer group. Sometimes the reason was geographical isolation but quite often it was rejection. Some peer groups apparently see themselves as not suitable for non-NHS doctors. One or two of the few people who called on the regional CPD coordinator to assist with this problem received no help.

\section{Participants' comments}

\section{College seminars and training}

The recurrent request that the College organise special seminars and training for portfolio practitioners could perhaps be considered by its Programmes and Meetings Committee, but it is difficult to get real commitment from members for such activities. One such meeting recently organised by the Postgraduate Education Department was very successful but poorly attended.

\section{The peer group}

The difficulty many members seem to have in understanding the essence of the College's approach to CPD creates its own handicap. It is important to emphasise that the peer group is at the heart of $\mathrm{CPD}$ for psychiatrists. The central regulations governing CPD are minimal and in any case subject to a certain amount of negotiation (e.g. internal $v$. external hours). The people who can agree or otherwise that a particular educational programme is appropriate for a particular member, taking into account previous experience and current professional activities, are those who form the CPD group. Each member should take the educational needs of the members seriously and give firm advice about what is required for the signature at the end of the year. No other members are in a position to know in detail what professional development means and is required for $\operatorname{Dr} \mathrm{X}$. This means that all of us need to take this aspect of our working year very seriously. Of course, the frequency of the peer group meetings, their size, the membership of the group and their activities are largely matters for the groups themselves. Nevertheless each group 
in a region should keep in contact with the regional CPD coordinator, who in turn should ensure the smooth running of the group system in that region and be in a good position to advise members who wish to change groups or join one.

\section{Financial cost of CPD}

The burden of cost for attending courses after retirement from full-time practice has not been considered by anybody, as far as I know. It's a complicated topic and impossible to discuss briefly here. No doubt, when it is discussed, as it should be, it will produce at least as much heat as light. One matter that can be fairly clearly stated however is that, despite the request from many retired practitioners, CPD can never be regarded in a partial manner. Halftime clinical practice does not require half-time CPD. One is either keeping up to the standard required for that practice or one is not. Partial standards are not acceptable because patients and other clients do not expect or pay for that.

\section{Exclusion and duplication}

Doctors fully employed within the independent sector clearly found CPD easier and had little difficulty in joining a peer group, but like private practitioners, including those who have recently retired from the NHS, they complained that they were excluded from NHS activities and seemed to have more trouble if they were not naturally within a peer group of the company that employed them.

The totally independent practitioners also had difficulty with CPD (just over a third of those wanting to retain their licence complaining about this) but they included quite a number of people who said they were undertaking private psychotherapy or psychoanalysis. Several of the latter indicated that psychotherapy professions have a separate form of CPD which could conflict with, duplicate or complicate the College procedures. Some in this group thought that medico-legal work doesn't require CPD! One wonders whence such an expert witness draws his or her expertise.

Nevertheless, one particular private practice group, which I have visited, resolved the problem of NHS 'exclusion' by organising itself into a small set of quasi-chambers and making its own arrangements for appraisal (including the employment of an NHS appraiser).

\section{The NHS ghetto?}

A constant theme in participants' comments was that there is no special attention given to the needs of psychiatrists who work outside the NHS. This was felt particularly strongly by members who are selfemployed. Most of us have heard of the expression 'middle-class ghetto'. Perhaps we should coin the term 'NHS ghetto' for the slightly superior and exclusive attitude that working for the NHS seems to engender.

In odd contrast, those who seemed to have most difficulty in doing CPD were the doctors who said they are in NHS practice. It turned out that most of them had 'retired' and were working part-time as locums for the NHS. The comments suggested that locum activity is particularly unsuited for CPD arrangements. It is worth noting, however, that locums placed through NHS Professionals (http://www.nhsprofessionals.nhs.uk) have the advantage that postgraduate education and CPD can be arranged for them.

\section{The 'others'}

In the heterogeneous 'others' group the members that stood out as expressing the most problems were those doctors undertaking mental health tribunal work. They are clearly uncertain as to whether CPD applies to them. They receive some training for their tribunal responsibilities, but this is probably focused quite narrowly, is legally biased and does not cover the breadth of issues that may confront a mental health tribunal doctor.

The 'others' group also illustrated the difficulty of prescribing one pattern of CPD for all, because a wide variety of psychiatrists, albeit in small numbers, do not conform to the standard NHS consultant model. Most of them are arguing, fairly persuasively, that their CPD ought to be tailored to their particular needs. This, of course, can be achieved within the College CPD peer group system, which provides sufficient flexibility for such individualisation.

\section{Recommendations}

I concluded the published report with a set of recommendations. Here I want to highlight one or two points that seem particularly important. One key conclusion that I reached from the data is that the College should be encouraged to run a voluntary appraisal system for those who are willing to subscribe to it. On the evidence of the survey (which, of course, reflects expressed intentions rather than actions) it would seem that the scheme would have quite a number of takers: over 200 if the results are really representative. I understand that the College is considering such a scheme and I would urge a rapid and positive decision. 
I came into medicine only a dozen or so years after the birth of the NHS and although I have worked for most of my professional life outside the NHS, employed by the University of London, most of my clinical work has been within the NHS. I fully understand therefore how and why the NHS has become so dominant in the Royal College of Psychiatrists. Furthermore, sometimes the College seems to concern itself almost entirely with the activities of the Department of Health in London, which is responsible for England and not the rest of the UK. This may seem inevitable given the disparity in size between the NHS and other medical practice and between England and other UK countries. However, this need not be inevitable and it's time that we grew away from this preoccupation with English government activity and gave more attention to psychiatry in its purest sense. Psychiatry was practised before the NHS was born and will continue after its demise. Psychiatry is practised elsewhere in the world, where there is no NHS. Doctors working outside the NHS have a unique contribution to make to any debate on professional standards. This should be more clearly reflected in College activities.

In line with the current trend for devolution within the College we should give more responsibility to our regional CPD coordinators and expect more from them. They are about to have their own training day each year, when they can be briefed on developments and problems, and they should be encouraged to ensure that everybody within their area - including every consultant practitioner outside the NHS - is undertaking CPD. Furthermore, they should be encouraged to help any individual who is having difficulty or doubt about which peer group or groups to join.

All our literature and our instructions to our regional CPD coordinators should make it clear that the responsibility for the standards of CPD, the programmes undertaken in the name of CPD and the personalisation of each individual's programmes should be the responsibility of the peer group. There should be no expectation that the central CPD Committee would set rules about this and that the only help available to a peer group, outside the group, would be the regional CPD coordinator.

\section{Declaration of interest}

J.G. is a portfolio psychiatrist and a member of the Royal College of Psychiatrists' CPD Committee.

\section{Reference}

Gunn, J. (2005) Survey of Retired and other non-NHS Members. Royal College of Psychiatrists. Royal College of Psychiatrists. http://www.rcpsych.ac.uk/docs/RetiredMembersurvey reportOct05.doc 